\title{
Правоведение
}

\author{
УДК 347
}

\section{А.И. Алимова}

\section{ПРОБЛЕМЫ ЮРИДИЧЕСКОЙ ОТВЕТСТВЕННОСТИ РАБОТОДАТЕЛЯ (ПО СТАТЬЕ 145.1 УК РФ)}

В статье представлен анализ состава преступления, предусматривающего ответственность за невыплату заработной платы и социальных выплат (ст.145.1 УК РФ). Рассмотрены вопросы межотраслевой дифференциации ответственности работодателей за невыплату заработной платы (материальной, административной, уголовной ответственности). Проведен сравнительный анализ особенностей правовой ответственности работодателей на невыплату заработной платы и иных выплат с точки зрения уголовного, уголовно-процессуального, административного и трудового законодательства Российской Федерации, который выявил большое количество проблем, требующих разрешения. В целом анализ проведенных ранее исследований по рассматриваемой проблеме свидетельствует о положительной динамике разрешения теоретико-прикладных проблем, но в то же время о наличии вопросов, которые до сих пор еще не решены, в частности, выявления особенностей объективных и субъективных признаков состава преступления, предусмотренного ст. 145.1 УК РФ. Указывается на необходимость формулирования и оценки предложений по квалификации преступления по ст. 145.1 УК РФ, определения критериев отграничения состава преступления по ст. 145.1 УК РФ от смежных и конкурирующих составов преступлений, что позволит на основании положений и выводов исследования сформулировать предложения по новой редакции ст. 145.1 УК РФ.

Ключевые слова: невыплата заработной платы, уголовная ответственность, объект, объективная сторона, субъективная сторона, работодатель, декриминализация преступления.

DOI: $10.35634 / 2412-9593-2020-30-5-689-696$

В современной юридической науке и практике весьма актуальным и интересным представляется вопрос рассмотрения особенностей правовой ответственности за невыплату заработной платы работникам на стыке отдельных отраслей права. Соблюдение прав, свобод и обязанностей человека и гражданина в трудовых отношениях, их защита и юридическая ответственность работодателей за правонарушения в сфере трудового законодательства являются одними из популярных в правовой сфере.

Часть 3 ст. 37 Конституции РФ закрепляет гарантию прав для работников на вознаграждение за труд, которое не должно быть ниже минимального размера оплаты труда [1]. Всеобщая декларация прав человека провозглашает право каждого работающего на вознаграждение, обеспечивающее достойное человека существование для него самого (ст. 23), а также на такой жизненный уровень, который необходим для поддержания здоровья и благосостояния его самого и его семьи, право на обеспечение на случай безработицы, болезни, инвалидности, вдовства, наступления старости или иного случая утраты средств к существованию по не зависящим от него обстоятельствам (ст. 25) [2].

Указанные гарантии реализуются путем установления определенных правил выплаты заработной платы. В частности, ст. 136 ТК РФ закрепляет, что заработная плата выплачивается не реже чем каждые полмесяца в день, установленный правилами внутреннего трудового распорядка, коллективным договором, трудовым договором [3]. Таким образом, невыполнение данного положения рассматривается как правонарушение, влекущее за собой различные виды юридической ответственности.

Во-первых, это материальная ответственность работодателя за задержку заработной платы и других выплат, причитающихся работнику в соответствии со ст. 236 ТК РФ. При нарушении работодателем установленного срока выплаты заработной платы и других выплат, причитающихся работнику, работодатель обязан выплатить их с уплатой процентов (денежной компенсации) в размере не ниже одной сто пятидесятой действующей в это время ставки рефинансирования Центрального банка Российской Федерации от невыплаченных в срок сумм за каждый день задержки, начиная со следующего дня после установленного срока выплаты по день фактического расчета включительно. Причем обязанность выплаты указанной денежной компенсации возникает независимо от наличия вины работодателя. Размер денежной компенсации, выплачиваемой работнику, может быть повышен как коллективным договором, так и локальным нормативным актом или трудовым договором. Пред- 
лагаем упростить формулу исчисления процентов от невыплаченных сумм, не связывая их со ставкой рефинансирования Центрального банка РФ, а, например, установив 1 \% от невыплаченных сумм.

Нарушение порядка выплаты заработной платы может подпадать и под норму Кодекса об административных правонарушениях РФ, предусмотренную ст. 5.27, а именно, нарушение законодательства о труде и об охране труда [4]. Объективная сторона указанного административного правонарушения включает такие деяния, как задержка заработной платы, занижение оплаты труда.

Статья 145.1 Уголовного кодекса РФ предусматривает уголовную ответственность за нарушения в сфере оплаты труда и выплат социального характера [5].

Таким образом, в действующем законодательстве РФ за правонарушения в сфере трудовых отношений предусмотрена административная ответственность физических и юридических лиц, материальная ответственность, а также уголовная ответственность работодателей. Правоприменитель должен иметь возможность четкой и однозначной дифференциации санкций: при любом факте нарушения конституционных прав граждан на вознаграждение за труд и социальное обеспечение в случаях, предусмотренных законом, лицо, виновное в этом нарушении (вне зависимости от наличия либо отсутствия прямого умысла, корыстной или личной заинтересованности), несет материальную ответственность перед лицом, право которого нарушено; при нарушении должностных обязанностей виновный несет административную ответственность; при наличии в действиях виновного лица признаков состава преступления, предусмотренного ст. 145.1 УК РФ, должна наступать уголовная ответственность.

В результате анализа законодательных актов, регулирующих право граждан на вознаграждение за труд, напрашивается вывод о существенной необходимости внесений изменений в диспозицию ст. 145.1. УК РФ, а также в ряд положений Трудового кодекса и Кодекса об административных правонарушениях с целью разрешения всех существующих коллизий.

Федеральныи законом РФ от 15 марта 1999 г. № 48-Ф3 была введена ст. 145.1 УК РФ «Невыплата заработной платы, пенсий, стипендий и иных выплат» [6]. Впоследствии ФЗ РФ от 23 декабря 2010 г. № 382-Ф3 норма ст. 145.1 получила новую редакцию [7]. Введение уголовно-охранительной нормы в сфере реализации конституционного права граждан на труд, а также на своевременную и в полном объеме выплату заработной платы было социально и экономически обусловлено массовым характером невыплаты заработной платы работникам. ФЗ РФ от 18 июля 1995 г. № 109-Ф3 была установлена уголовная ответственность за задержку выплату заработной платы, а именно, ст. 138 УК РСФСР «Нарушение законодательства о труде», которая действовала до 1 января 1997 г., - даты вступления в силу УК РФ 1996 г., который в свою очередь в первоначальной редакции уголовную ответственность за невыплату заработной платы не предусматривал [8].

В контексте сравнительного правоведения слудует отметить, что в подавляющем большинстве уголовных законов зарубежных государств отсутствует норма, аналогичная ст. 145.1 УК РФ. При невыплате социальных выплат ответственность в этих странах наступает (при наличии соответствующего основания) по нормам общего характера. Законодательство стран общего права содержит исключительно гражданско-правовую и административную ответственность за невыплату заработной платы и иных социальных выплат.

В отечественной уголовно-правовой науке также высказываются мнения о том, что конструирование специальных норм (в том числе и ст. 145.1 УК РФ) при наличии в Кодексе общих норм (ст. 201 и 285 УК РФ) криминологически необоснованно, с которыми можно отчасти согласиться. Кроме того, как ученые, так и законодатели в настоящее время справедливо высказывают предложения о декриминализации ст. 145.1 УК РФ как излишне вменяемой, социально и экономически необоснованной.

В сложившихся социально-экономических условиях функция исследуемой нормы, как доказывает правоприменительная практика, в большей мере профилактическая. Дальнейшее совершенствование уголовно-правовой охраны права на вознаграждение за труд и получение гарантированных социальных выплат должно быть ориентировано, в первую очередь, на восстановление прав лиц, понесших имущественный вред от преступления. Всецело поддерживаем предложения о включении в КоАП РФ статьи, предусматривающей ответственность за невыплату в срок менее двух месяцев вознаграждения за труд, пенсий, стипендий, пособий и иных гарантированных социальных выплат, установленных федеральными, региональными и местными нормативными актами, либо их неполную выплату в сумме больше MPOT. 
Проблемы юридической ответственности работодателя (по статье 145.1 УК РФ)

691

ЭКОНОМИКА И ПРАВО

2020. Т. 30, вып. 5

Статья 145.1 УК РФ предусматривает уголовную ответственность руководителей организаций за невыплату заработной платы, пенсий, стипендий, и иных пособий, совершенных с корыстной и иной личной заинтересованностью, свыше двух и трех месяцев в полном и частичном размере соответственно.

Принципиально важным,на наш взгляд, является наличие в качестве структурного элемента ст. 145.1 УК РФ примечания, формулирующего специальные основания освобождения от уголовной ответственности - лицо, впервые совершившее преступление, предусмотренное чч. 1 и 2 данной статьи, освобождается от уголовной ответственности, если в течение двух месяцев со дня возбуждения уголовного дела оно в полном объеме погасило задолженность по выплате заработной платы, пенсии, стипендии, пособия и иной установленной законом выплате, а также уплатило проценты (выплатило денежную компенсацию) в порядке, определяемом законодательством Российской Федерации, и в его действиях не содержится иного состава преступления.

Сравнительный метод познания, используемый в данном исследовании, которое посвящено анализу межотраслевой дифференциации и особенностям правовой ответственности работодателей на невыплату заработной платы и иных выплат с точки зрения уголовного, уголовно-процессуального законодательства, административного и трудового законодательства Российской Федерации, выявляет большое количество проблем, требующих разрешения. В целом анализ проведенных исследований по рассматриваемой проблеме указывает на положительную динамику решения теоретико-прикладных проблем, но в то же время свидетельствует о наличии нерешенных вопросов в сфере выявления особенностей объективных и субъективных признаков состава преступления, предусмотренного ст. 145.1 УК РФ. Также необходимы разработка предложений по квалификации преступления, определение критериев отграничения состава преступления по ст. 145.1 УК РФ от смежных и конкурирующих составов преступлений, предложения по новой редакции ст. 145.1 УК РФ.

Уголовно-правовая практика применения ст. 145.1 УК РФ в структуре общеуголовной преступности и динамика роста относительно небольшие, но за последние 5 лет количество уголовных дел, возбужденных по данной статье, вновь стало увеличиваться. Поэтому исследование особенностей применения норм УПК РФ и практики привлечения работодателей к уголовной ответственности по ст. 145.1 УК РФ представляется актуальным.

Статья 145.1 находится в главе УК РФ о преступлениях против конституционных прав и свобод человека и гражданина, что и позволяет рассматривать объект этого преступления как общественные отношения в сфере реализации прав человека, в частности, права на труд.

Под непосредственным объектом преступления, предусмотренного ст. 145.1 УК РФ, понимаются общественные отношения в сфере социально-экономической политики государства в процессе реализации конституционных прав человека и гражданина, обеспечивающие каждому право на вознаграждение за труд (ч. 3 ст. 37 Конституции РФ); право на социальное обеспечение по возрасту, в случае болезни, инвалидности, потери кормильца, для воспитания детей и в иных случаях, установленных законом (ст. 39 Конституции РФ); право на образование (ч. 1 ст. 43 Конституции РФ), то есть система отношений, складывающихся между управомоченными субъектами и работодателями, уполномоченными органами по поводу установления и осуществления выплаты вознаграждения за труд и социальных выплат.

Предметом анализируемого преступления являются выплаты, установленные нормами трудового законодательства: заработная плата, доплаты, надбавки, пособия и прочие выплаты, входящие в систему заработной платы.

В юридической литературе отдельные авторы предлагают заменить детализированное перечисление различного рода выплат в ст. 145.1 УК РФ на единую комплексную категорию, которая будет включать содержание всех данных выплат, а именно, установленные нормами трудового законодательства выплаты. Представляется, что подобный подход к пониманию предмета исследуемого преступления не будет способствовать уголовно-правовой реализации нормы по ст. 145.1 УК РФ и судебной перспективе.

Вместе с тем конкретное указание в законе всех выплат, а именно, заработной платы, пенсий, стипендий, пособий и иных гарантированных социальных выплат, установленных федеральными, региональными и местными нормативными актами, а также страховых взносов на обязательное пенсионное страхование работников, по мнению автора, будет способствовать приведению в соответствие норм Трудового кодекса РФ и Уголовного кодекса РФ. 
Состав преступления по ст. 145.1 УК РФ имеет место как при полной невыплате, а также при выдаче заработной платы в размере, меньшем установленного федеральным законом минимального размера оплаты труда, в том числе и при оплате месячной нормы рабочего времени ниже прожиточного минимума трудоспособного человека, и, наконец, при выплате в размере ниже прожиточного минимума работника и нетрудоспособных членов его семьи. Поэтому объективную сторону исследуемого преступления необходимо понимать как полную невыплату или частичную задержку выплаты вознаграждения за труд, пенсий, стипендий, пособий и иных гарантированных социальных выплат, установленных федеральными, региональными и местными нормативными актами, используя для определения частичной невыплаты заработной платы критерий МРОТ.

Следует отметить, что объективная сторона преступления по ст. 145.1 УК РФ выражена деянием в виде бездействия свыше определенного законом срока, а именно невыплатой заработной платы, пенсий, стипендий и иных пособий. В связи с чем возникает необходимость проведения судебнобухгалтерской экспертизы с целью анализа бухгалтерской, учредительной и иной финансовой документации на предмет правильности исчисления и отражения в бухгалтерских документах заработной платы.

Что же касается проведения судебно-экономической экспертизы и ревизии, которые могут отчасти дублировать судебно-бухгалтерскую экспертизу, необходимо изначально в рамках судебнобухгалтерской экспертизы поставить перед экспертом соответствующие вопросы, в том числе и касающиеся финансового положения организации. Длительные сроки проведения судебно-бухгалтерской и судебно-экономической экспертиз влияют на общий срок предварительного расследования по делу и существенно его увеличивают.

В рамках объективной стороны должны быть установлены два самостоятельных признака: а) деяние, выраженное в форме бездействия, - «невыплата» и б) время (длительность) этого бездействия - «свыше двух месяцев». Следует учитывать совокупность условий, определяющих противоправность бездействия: а) законно возложенная обязанность выплачивать социальные платежи на ответственного за выплату субъекта; б) фактическая невыплата при наличии реальной возможности произвести ее в сложившейся обстановке; в) длительность невыплаты сроком свыше двух месяцев.

Отсчет двухмесячного срока начинается со следующего после установленной даты выдачи зарплаты, стипендии, пенсии и иной выплаты дня. При совпадении установленного дня выплаты заработной платы с выходным или нерабочим праздничным днем отсчет двухмесячного срока по ст. 145.1 УК РФ правильно производить со следующих суток за выходным или нерабочим праздничным днем. По смыслу ст. 145.1 УК РФ имеются в виду два календарных месяца (т. е. нерабочие дни не подлежат исключению из подсчета), речь идет о непрерывных невыплатах, невыплатах (как уголовно-правовом бездействии) подряд в течение указанного срока. Упомянутый в диспозиции ст. 145.1 УК РФ признак «свыше двух месяцев» определяет длительность бездействия. В связи с этим невыплата свыше двух месяцев, например, заработной платы за один отработанный месяц, даже при оплате последующих отработанных месяцев, формально подпадает под признаки состава ст. 145.1 УК РФ. Это означает, что оценке при квалификации преступления должен быть подвергнут каждый месяц невыплаты в сочетании со всеми признаками состава преступления (предметом преступления, признаками субъективной стороны преступления, единым субъектом преступления) и в сумме составляющий период свыше двух месяцев. Общественная опасность содеянного прежде всего заключается в том, что потерпевший на длительное время (как минимум, свыше двух месяцев) лишается средств к существованию.

С субъективной стороны преступление, предусмотренное ст. 145.1 УК РФ, характеризуется умышленной формой вины. Вина по ст. 145.1 УК РФ имеет сложный характер, обусловленный специфичными формами выражения вовне поведения лица. Если юридическое (уголовно-правовое) бездействие осуществляется в форме действия (например, прямого отказа выплачивать соответствующие выплаты), то имеет место прямой умысел. Несколько иная ситуация может возникнуть при осуществлении невыплаты посредством бездействия (например, при затягивании свыше двух месяцев оплаты причитающихся выплат, непринятии мер по погашению дебиторской задолженности и т.п.). Здесь может иметь место и косвенный умысел.

Субъективная сторона преступления характеризуется также и обязательными мотивами - корыстной или иной личной заинтересованностью. Корыстная заинтересованность выражается в стремлении получить для себя или других лиц выгоды имущественного характера, в том числе погашение 
Проблемы юридической ответственности работодателя (по статье 145.1 УК РФ)

693

ЭКОНОМИКА И ПРАВО

2020. Т. 30, вып. 5

кредитов, уплату налогов, освобождение от имущественных затрат и т. д. Корысть как мотив совершения преступления, по мнению Б.С. Волкова, «означает, что в основе побудительных причин общественно опасного деяния лежит стремление получить какую-нибудь материальную выгоду, пользу» [9. С. 45]. Личная заинтересованность выражается в первую очередь в стремлении получить выгоды лично для себя, в том числе и неимущественного характера.

При совершении деяния по ст. 145.1 УК РФ из иной личной заинтересованности должны быть указаны выгоды неимущественного характера, для реализации которых виновный не выплачивал причитающиеся платежи, конкретные побуждения, которыми он руководствовался. Таким образом, иная личная заинтересованность по ст. 145.1 УК РФ предполагает установление по делу двух групп фактических данных: а) свидетельствующих о стремлении виновного извлечь выгоды неимущественного характера и б) подтверждающие обусловленность этого стремления побуждениями, не вызванными необходимостью и не отвечающими требованиям общественной полезности.

Корыстная или иная личная заинтересованность в деятельности руководителя - обязательный элемент состава преступления, предусмотренного ст. 145.1 УК РФ, который подтверждается анализом движения денежных средств по расчетным счетам организации, сведения о которых содержатся в налоговом органе, на учете которого стоит организация. На основании этого можно сделать выводы, имелись ли на счетах организации денежные средства для погашения задолженности по заработной плате и иным выплатам; какие статьи расходов использовались в период образования задолженности.

В практике деятельности органов предварительного следствия затруднения вызывает установление умысла в действиях руководителей организации при расследовании уголовных дел о невыплате заработной платы, то есть определение субъективной стороны состава преступления. Отметим, что умысел руководителя проявляется не только в самом факте задержки заработной платы, но и в реальной возможности своевременно выплачивать заработную плату, что может быть установлено с помощью также судебно-бухгалтерской экспертизы. Кроме того, с целью восстановления прав работников, возмещения ущерба существует необходимость установления имущественного положения руководителя организации и самой организации.

Так, приговором Ленинского районного суда г. Ульяновска был осужден М. по ч. 2 ст. 145.1 УК РФ, предусматривающей ответственность за полную невыплату заработной платы работника при наличии реальной возможности своевременно выплачивать заработную плату, что было доказано выплатами за обучение ребенка в вузе со счетов организации за вменный период времени.

Часть 2 ст. 145.1 УК РФ содержит самостоятельный состав преступления, объективная сторона этого деяния выражается: 1) в полной невыплате свыше двух месяцев заработной платы, пенсий, стипендий, пособий и иных выплат; 2) в выплате заработной платы свыше двух месяцев ниже установленного федеральным законом минимального размера оплаты труда (далее - МРОТ). Таким образом, данная норма устанавливает ответственность за нарушение гарантированного международноправовыми актами и Конституцией РФ минимального размера оплаты труда.

Тяжкие последствия невыплаты заработной платы и иных установленных законом выплат являются квалифицирующим признаком, закрепленным в ч. 3 ст. 145.1 УК РФ, и подлежат установлению: смерть работника либо члена семьи, находящаяся в причинно-следственной связи с невыплатой заработной платы, вынужденный переезд, тяжелая болезнь потерпевшего или его родственника. Вместе с тем предусмотренный законодателем квалифицирующий признак «тяжкие последствия» в уголовно-правовой норме детально не конкретизирован. Этот вывод подтверждается и тем, что при изучении судебной практики не было найдено уголовных дел, возбужденных по признаку причинения тяжких последствий в связи с невыплатой заработной платы (ч. 3 ст. 145.1 УК РФ). Поэтому целесообразно уточнить возможные тяжкие последствия исследуемого преступления, указав в ч. 2 признак «крупный размер» (превышающий $50 \mathrm{MPOT),} \mathrm{и} \mathrm{ч.} \mathrm{3,} \mathrm{в} \mathrm{которой} \mathrm{указать} \mathrm{признак} \mathrm{«особо} \mathrm{крупный} \mathrm{раз-}$ мер» (превышающий 100 МРОТ). Определение суммарного объема невыплат может оказаться более объективным квалифицирующим признаком исследуемого преступления.

Время и место совершения деяния по ст. 145.1 УК РФ предусматриваются в качестве элемента объективной стороны - наличие задолженности по выплатам свыше двух (для ч. 2 ст. 145.1 УК РФ) и трех (для ч. 1 ст. 145.1 УК РФ) месяцев. При этом законом не установлено, что месяцы должны идти подряд. В связи с чем при определении момента окончания преступления следует учитывать месяцы, в которые была допущена невыплата социальных платежей, вне зависимости от их очередности. При этом преступление признается оконченным по истечении двух месяцев (при полной невыплате) или 
трех месяцев (при частичной невыплате) начиная с 00 часов суток, следующих за днем, когда должны были быть произведены указанные ст. 145.1 УК РФ платежи. Указанные даты могут быть установлены законодательством или локальными нормативными актами. Моментом, с которого должен исчисляться трехмесячный и двухмесячный срок, следует считать день, следующий за днем, на который, согласно трудовому законодательству, соглашению, коллективному договору и иным локальным нормативным правовым актам, приходится выплата.

Однако существуют и иные точки зрения на данный аспект объективной стороны, например, что двухмесячный срок, предусмотренный ч. 2 ст. 145.1 УК РФ, следует отсчитывать со дня, установленного для осуществления соответствующих выплат, таким образом, указанное преступление рассматривается как продолжаемое.

Субъектом преступления в действующей редакции ст. 145.1 УК РФ определен руководитель организации, работодатель - физическое лицо, руководитель филиала, представительства или иного обособленного структурного подразделения организации. Вместе с тем субъектом данного преступления органами предварительного следствия признаются не только должностные лица, но и лица, выполняющие управленческие функции в коммерческой или иной организации. Подход, используемый органами предварительного расследования при определении субъекта по ст. 145.1 УК РФ, позволяет привлекать в качестве подозреваемого и обвиняемого лицо, фактически осуществляющее руководство организацией, то есть не назначенное на должность соответствующим приказом. Такая формулировка присутствует в ходатайствах в суд о производстве обыска жилища, в том числе и лиц, проходящих в качестве свидетелей по уголовным делам по ст. 145.1 УК РФ. В свою очередь суды удовлетворяют подобные ходатайства для производства следственных действий.

Согласно ст. 142 ТК РФ, ответственность за нарушение сроков выплаты заработной платы и иных сумм, причитающихся работнику, несут работодатель и (или) уполномоченные им в установленном порядке представители работодателя, допустившие задержку выплаты работникам заработной платы и другие нарушения оплаты труда.

В научной литературе встречаются различные предложения об изменении названия ст. 145.1 УК РФ в части унификации понятия различных выплат: «Невыплата социальных выплат» [10. С. 5], что вызывает обоснованные возражения, поскольку правовая природа заработной платы иная, чем у социальных выплат. Спорным и с практической точки зрения является предложение о необходимости замены детализированного перечисления различного рода выплат в диспозиции ст.145.1 УК РФ на единую комплексную категорию, которая соединит в себе содержание всех данных выплат - «установленные нормами трудового законодательства выплаты». Предлагается и новая редакция ст. 145.1 УК РФ с заменой понятия заработной платы на более широкое - вознаграждение за труд, с указанием уровня выплат, связи размера выплат с МРОТ, применением понятий невыплаты и задержки со сроком свыше двух месяцев [11. С. 13,14 ], что также спорно и вызывает множество вопросов и требует разъяснений.

Можно считать целесообразным при отграничении административного нарушения и преступлений, связанных с незаконными невыплатами, дополнение содержания диспозиции прямым указанием на умышленный характер невыплаты.

В целях закрепления минимального порога общественной опасности также предлагают предусмотреть преступность невыплаты, совершенной в крупном размере. Под крупным размером следует понимать невыплату, превышающую в двукратном размере среднюю заработную плату в субъекте Федерации [12. С. 8,9].

Исследователи рассматривают различные варианты разграничения преступления и административного правонарушения, в частности, форму вины - умысел, например, при квалификации невыплаты заработной платы по ст. 145.1 УК РФ, а также крупный размер невыплаты. Кроме того, авторы практически единодушны в необходимости изменения понятия предмета преступления и предлагают заменить перечисление выплат на единую категорию, а именно, на «установленные законом выплаты», «социальные выплаты», «вознаграждение за труд», таким образом изменив предмет посягательства.

Вместе с тем введение единого комплексного термина, например, такого как установленные законом выплаты или социальные выплаты, может повлечь неоправданно широкое и неверное понимание предмета преступление, что затруднит практику применения ст. 145.1 УК РФ, которая в действующей редакции является бланкетной. Общественная опасность деяний, предусмотренных УК РФ, предполагает детализацию, а значит, конкретизацию описания преступного поведения в диспозиции уголовно-правовой нормы. 
Каждый термин уголовно-правовой нормы, предусмотренной ст. 145.1 УК РФ, несет свою смысловую нагрузку и обеспечивает жизненно важные социально-экономические потребности человека. Изменение терминологии УК РФ, которая должна быть четкой, емкой и лаконичной, одновременно вызывает необходимость внесения серьезных изменений в ТК РФ, УПК РФ и КоАП РФ. В противном случае правоприменителю будет сложно разграничить преступное от непреступного, это в свою очередь повлечет совершение практических ошибок и затормозит реализацию ст. 145.1 УК РФ.

Таким образом, можно говорить о двух ярко выраженных подходах к правовой регламентации ст. 145.1 УК РФ, предлагаемых в научной литературе, а именно, криминализации деяния в части субъектного состава преступления и декриминализации невыплаты заработной платы, а именно, частичной невыплаты.

Думается, что в современных реалиях необходимости строгой самоизоляции, обусловленной пандемией, прекращения деятельности коммерческих организаций малого и среднего бизнеса, мирового экономического спада, не целесообразно применять ст. 145.1 УК РФ, используя правила крайней необходимости либо декриминализировать данную нормы на законодательном уровне.

\section{СПИСОК ЛИТЕРАТУРЫ}

1. Конституция Российской Федерации (принята всенародным голосованием 12 дек. 1993 г.) // С3 РФ. 2009. № 4. Ст. 445 .

2. Всеобщая декларация прав человека от 10 декабря 1948 г.

3. Трудовой кодекс Российской Федерации от 30 дек. 2001 № 197-Ф3 // С3 РФ. 2002. № 1, ч. 1. Ст. 3.

4. Кодекс Российской Федерации об административных правонарушениях от 30 дек. 2001 г. № 195-Ф3 // С3 РФ. 2002. № 1, ч. 1. Ст. 1.

5. Уголовный Кодекс Российской Федерации от 13 июня 1996 № 63-ФЗ // СЗ РФ. 1996. № 25. Ст. 2954.

6. Федеральный закон Российской Федерации от 15 марта 1999 г. № 48-Ф3 «О дополнении Уголовного кодекса Российской Федерации статьей 145.1» // С3 РФ. 1999. № 11. Ст. 1255.

7. Федеральный закон Российской Федерации от 23 дек. 2010 г. № 382-Ф3 «О внесении изменения в статью 145.1 Уголовного кодекса Российской Федерации» // С3 РФ. 2010. № 52, ч. 1. Ст. 6997.

8. Закон Российской Федерации от 18 июля 1995 г. № 109-Ф3 «О внесении изменений и дополнений в Кодекс законов о труде Российской Федерации, Основы законодательства Российской Федерации об охране труда, Кодекс РСФСР об административных правонарушениях и Уголовный кодекс РСФСР» // СЗ РФ. 1995. № 30. Ст. 2865.

9. Волков Б.С. Мотивы преступления. Казань: Изд-во Казан. ун-та, 1982. 152 с.

10. Соктоева Е.И. Уголовная ответственность за невыплату заработной платы, пенсий, стипендий, пособий и иных выплат: по материалам судебной и прокурорской практики Уральского, Сибирского и Дальневосточного федеральных округов: автореф. дис. ... канд. юрид. наук. М., 2005. С. 23.

11. Панкратова О.В. Невыплата заработной платы, пенсий, стипендий, пособий и иных выплат (ст. 145.1 УК РФ): уголовно-правовой и криминологический аспекты: автореф. дис. ... канд. юрид. наук. Краснодар, 2012. C. $10-14$.

12. Кокорин Д.Л. Уголовно-правовая характеристика невыплаты заработной платы: автореф. дис. ... канд. юрид. наук. Тюмень, 2009. С. 22.

Поступила в редакцию 22.05.2020

Алимова Анжелика Ирековна, кандидат юридических наук, доцент кафедры менеджмента и права ФГБОУ ВО «Ижевская государственная сельскохозяйственная академия»

426069, Россия, г. Ижевск, ул. Студенческая, 11.

E-mail: a-alimova-27@mail.ru

\section{A.I. Alimova \\ PROBLEMS OF LEGAL LIABILITY OF THE EMPLOYER (ACCORDING TO ARTICLE 145.1 OF THE CRIMINAL CODE OF THE RUSSIAN FEDERATION)}

DOI: $10.35634 / 2412-9593-2020-30-5-689-696$

The article presents the analysis of a crime, providing for liability for non-payment of wages and social benefits (article 145.1 of the Criminal Code of the Russian Federation). The issues of cross-sector differentiation of employers' liability 
for non-payment of wages (material, administrative, criminal liability) are considered. A comparative analysis of the specifics of employers' legal liability for non-payment of wages and other payments was made in terms of criminal, criminal procedural, administrative and labor legislation of the Russian Federation, which revealed a large number of problems that need to be resolved. In general, the analysis of earlier studies on this problem shows positive dynamics of resolution of theoretical and applied problems, but at the same time there are issues that have not yet been resolved, in particular, the identification of features of objective and subjective features of the crime under Article 145.1 of the Criminal Code of the Russian Federation. It is pointed out that it is necessary to formulate and evaluate proposals on qualification of a crime under Article 145.1 of the Criminal Code of the Russian Federation, define criteria for delimitation of the crime under Article 145.1 of the Criminal Code from related and competing crimes, which will make it possible to formulate proposals on the new version of Article 145.1 of the Criminal Code based on the provisions and conclusions of the research.

Keywords: non-payment of wages, criminal liability, object, objective side, subjective side, employer, decriminalization of crime.

Alimova A.I., Candidate of Law, Associate Professor Izhevsk State Agricultural Academy

Studencheskaya st., 11, Izhevsk, Russia, 426069

E-mail: a-alimova-27@mail.ru 